\title{
A História Geral de Delgado de Carvalho: uma coleçáo entre CRÍTICAS E DISCORDÂNCIAS (1950-1960)*
}

\author{
Patrí́cia COelho**
}

\begin{abstract}
Resumo
Este texto analisa os debates ocorridos na década de 1950, em torno da coleção História Geral. Elaborada por Carlos Delgado de Carvalho, professor catedrático de História Moderna e Contemporânea da Universidade do Brasil, a obra, composta por quatro volumes, destinava-se ao aperfeiçoamento de professores secundários. Publicada pelo Instituto Nacional de Estudos Pedagógicos (INEP), a coleção foi considerada retrógrada por historiadores da Universidade de São Paulo, por não seguir os preceitos da Escola dos Annales. O estudo de tais conflitos do campo científico nos revela tanto questóes didáticas quanto aspectos da orientação metodológica dada aos mestres, possibilitando, assim, novas visóes dessa disciplina escolar.
\end{abstract}

Palavras-Chave: disciplina escolar, conflitos, campo científico, História.

\section{Delgado de Carvalho's General History: a collection of criticism and discordance (1950-1960)}

\section{Abstract}

This paper examines the debates that occurred in the 1950s about the general History collection. Developed by Carlos Delgado de Carvalho, Professor of Modern and Contemporary History at Universidade do Brasil (University of Brazil), the work, consisting of four volumes, was intended to be used for high school teachers' professional development. Published by the National Institute of Pedagogical Studies (INEP), the collection was considered retrograde by historians of the University of São Paulo, for not following the precepts of Annales School. The study of such conflicts in the scientific field reveals both didactic issues and methodological orientation aspects given to teachers, thus allowing new visions of this school discipline.

KEY wORDS: school discipline, conflicts, scientific field, History.

Este texto compreende uma versão de parte do terceiro capítulo da dissertação $A$ voz do mestre: trajetória intelectual de Carlos Delgado de Carvalho, defendida pela autora na Faculdade de Educação da Universidade do Estado do Rio de Janeiro (UERJ), em julho de 2007.

** Doutoranda do Programa de pós-graduação em Educação da Universidade de São Paulo. Bolsista FAPESP. E-mail: pacoel@bol.com.br 
A coleção História Geral foi elaborada por Carlos Delgado de Carvalho para o programa do INEP (Instituto Nacional de Estudos Pedagógicos) denominado Caldeme (Campanha do Livro Didático e Manuais de Ensino), realizado na gestão de Anísio Teixeira, na década de 1950. A Caldeme consistia em um projeto de assistência técnica ao professorado, por meio de manuais elaborados por pessoas de reconhecida autoridade científica. Tais obras deveriam fornecer o embasamento teórico que, ao olhar dos educadores ligados ao programa, faltava aos nossos mestres.

Para Bourdieu (1989), os intelectuais formam um campo, a partir de um setor da sociedade, no qual os indivíduos produzem e lutam pelo controle da produção, ou seja, pelo direito de legitimar sua autoridade sobre um determinado conhecimento, conseguindo o reconhecimento de seus pares, em uma hierarquia. O que está em jogo no campo intelectual é o monopólio da autoridade científica. Sete intelectuais que desfrutavam de tal autoridade - definida por Bourdieu (1983, p. 123) como "a capacidade de falar e de agir legitimamente (isto é, de maneira autorizada e com autoridade) que é socialmente outorgada a um agente determinado" - foram convidados para a elaboração dos manuais: Paulo Sawaya, Karl Arens, Oswaldo Frota Pessoa, Mário de Sousa Lima, Raymond Der Haegen, Américo Jacobina Lacombe e Carlos Delgado de Carvalho, sendo este último o foco desta análise.

Educado na Europa, onde se doutorou em História Diplomática pela Escola de Ciências Políticas de Paris, Delgado de Carvalho chegou ao Brasil em 1906, quando passou a divulgar, com seus livros, conhecimentos de geografia, sociologia e história, que contribuíram para a organização do nosso campo científico. Professor do Colégio Pedro II, transformou o ensino da nossa geografia ao apresentar aos nossos estudantes secundaristas, em Geographia do Brasil (1913), o país dividido em cinco regióes - septentrional, nordestino, oriental, meridional e central -, superando os critérios apenas administrativos anteriormente usados para classificar as regiōes naturais. As demais 48 obras publicadas pelo intelectual sempre tiveram grande preocupaçáo didática, combatendo o ensino baseado apenas na memorização. Signatário do Manifesto dos Pioneiros da Educação Nova (1932), junto com Anísio Teixeira e Fernando de Azevedo, compartilhou com esses companheiros a expectativa de que a educaçáo poderia transformar a nação. Ao lado deles, também participou da implantação do curso de Geografia na Universidade do Distrito Federal (UDF). Com a 
extinção da UDF em 1939 e a incorporação de seus cursos à Universidade do Brasil, Delgado de Carvalho tornou-se catedrático de História Moderna e Contemporânea.

Ao organizar os quatro volumes de História geral - História Geral: antiguidade compêndio de informaçôes para uso dos docentes (1956); História Geral: Idade média (1959), em dois tomos; e História Geral: Idade contemporânea (1966) -, Delgado de Carvalho demonstrou claramente sua preocupação com a didática dessa disciplina. $\mathrm{O}$ conteúdo dividido em Idade Antiga, Idade Média (composto de duas unidades), Idade Moderna e Idade Contemporânea eram ilustrados com mapas, personagens históricos, tinham sugestóes de quadros de sistematização, tudo que aproximasse, a seu ver, os alunos da realidade histórica.

À época da elaboração da coleção, nosso campo científico passava por mudanças. Havia um intenso desejo de romper com o pouco dedicado à pesquisa na área das ciências sociais. Nesse sentido, o Centro Brasileiro de Pesquisas Educacionais (CBPE) era um projeto para integrar educadores e cientistas. $\mathrm{O}$ campo das ciências sociais já há muito se modificara com a influência de professores estrangeiros que, a partir da década de 1930, ministraram cursos nas recém-criadas Universidade de Sáo Paulo (USP) e Universidade do Distrito Federal (UDF), delimitando novas linhas de pensamento, que alargaram a perspectiva das investigaçóes científicas. Fruto dessas transformações, a geração de historiadores que atuava nos anos 1950 pressupunha assim novos métodos, a partir dos pressupostos da Escola dos Annales. A discussão acadêmica deveria estar presente nos livros didáticos a partir de uma visão mais global do contexto histórico, afastando um olhar apenas político, o que pedia não só uma nova divisão dos conteúdos, como também da forma de apresentá-los. Um exemplo da nova orientação seria a adoção de termos que definissem de forma mais adequada tal processo, por isso, vocábulos que permitissem generalizaçôes deveriam ser evitados.

As discordâncias e críticas foram inevitáveis. Os avaliadores da obra de Delgado de Carvalho, pertencentes à nova geração de historiadores, o acusavam de retrógrado. $\mathrm{O}$ diálogo, registrado por meio de correspondência, servem de fonte para este estudo. A partir de sua análise é possível compreender como as disputas no campo científico influenciaram a composição da disciplina escolar, mediante a orientação dada aos professores por meio dos manuais. Tais discussóes também revelam aspectos da cultura material escolar que envolvia a disciplina. 


\section{Revista Solta a Voz, v. 20, n. 2}

\section{Os MANUAIS EM DISCUSSÃO}

Ao assumir a presidência do Instituto Nacional de Estudos Pedagógicos (INEP) em 4 de julho de 1952, Anísio Teixeira (1952, s.p.) traça a seguinte meta para sua administração:

Esforçar-nos-emos por aplicar métodos objetivos e, quando possível, experimentais, mas tudo conduziremos com o sentimento profundo do caráter provisório do conhecimento, mesmo quando ou, talvez, sobretudo, quando científico. A ciência não nos vai fornecer receitas para as soluçôes dos nossos problemas, mas itinerário de um caminho penoso e difícil, com idas e voltas, ensaios e verificaçóes e revisóes, em constante reconstrução, a que não faltará, contudo, a unidade de essência, de fins e objetivos, que estará contida não só na lei de bases e diretrizes como na consciência profissional, que pouco a pouco se irá formando entre os educadores. Será por este modo que o Instituto pensa se deixar conduzir pelo método e espírito científico.

Ao aceitar o convite para o cargo, o educador vislumbrava realizar o antigo ideal de unir a ciência à prática educacional. A análise de Mendonça (1997) destaca que tal projeto previa a aplicação do conhecimento científico em três níveis da atividade educativa: na organização e gestão dos serviços escolares, na formação dos professores e, por fim, no interior mesmo da escola, onde era preciso introduzir o que Teixeira chamava de espírito científico, percebido quase como sinônimo de espírito experimentalista, de investigação, de pesquisa.

Ainda que Anísio Teixeira combatesse a cultura livresca da escola, distante da realidade e que pouco conseguia acrescentar à trajetória do aluno, não deixava de reconhecer o livro como recurso fundamental em qualquer sistema educacional. Para se transformar os métodos, não se deveria e nem se poderia abrir mão de livros, apenas utilizá-los de outra forma. Assim como outros educadores de sua geraçáa, ele acreditava no livro didático como propagador de conhecimentos, capaz de levar a distância informaçóes importantes para a formação e a prática pedagógica. Ao anunciar, no discurso de posse, seu programa de mudanças à frente do INEP, assim declara:

Este trabalho, pois, não será nenhum trabalho remoto e distante, mas parte integrante e preliminar do programa de reconstrução de nossas escolas e revisão de seus métodos. Não será por leis, mas por estudos, que daremos 
início à reforma do ensino, que todos anseiam, mas temem, com fundado receio de que se transforme em mais uma experiência frustrada de alteração de nomes ou de posição de elementos no complexo da situação educacional. Se conseguirmos, porém, os estudos objetivos que aqui sugerimos, e sôbre eles fundarmos diagnósticos válidos e aceitos, não será difícil a elaboração dos métodos de tratamento e indicação dos prognósticos. Os métodos de tratamento surgirão nos guias e manuais de ensino para os professores e diretores de escolas, os quais constituirão livros experimentais de sugestôes e recomendaçóes, para a condução do trabalho escolar. Em complemento, deveremos chegar até o livro didático, compreendendo o livro de texto e o livro de fontes, buscando integrar nestes instrumentos de trabalho o espírito e as conclusóes dos inquéritos precedidos. (CBPE, 1956, p. 16)

$\mathrm{Na}$ exposição de motivos da Caldeme, Anísio Teixeira argumenta que, diante da falta de recursos para promover cursos de aperfeiçoamento necessários, principalmente no interior, a solução seria "fazer chegar às suas mãos guias ou manuais escritos especialmente para a sua orientação" (CBPE, 1956, p. 21). Sem dúvida, o custo de elaboração desses manuais era infinitamente menor e, distribuídos por todo o Brasil, estariam cumprindo a tarefa, ainda que não da maneira considerada ideal, de proporcionar formação continuada aos professores. Para atingir tal objetivo, o diretor do INEP estabeleceu como critério para seleção dos autores que fossem intelectuais capazes de atrelar o conhecimento à criação de novas técnicas de ensino.

A dificuldade inicial maior foi encontrar pessoas que aliassem a reconhecida competência a dois outros indispensáveis qualificativos: uma convicção segura dos males provindos entre nós do ensino verbalista e um entusiasmo tal pelas vantagens de uma mudança radical nesse ensino que as levassem a se dedicarem à penosa tarefa de elaboração dos manuais, com sacrifício parcial embora, de outras atividade profissionais. (CBPE, 1956, p. 31)

Anísio Teixeira justificou a escolha de Delgado de Carvalho:

[...] catedrático de história moderna e contemporânea na Faculdade Nacional de Filosofia, autor de vários estudos sobre a renovação do ensino secundário das ciências sociais (êste nome dispensa informaçôes adicionais, tão conhecidos são os seus trabalhos sôbre geografia, história e sociologia). (CBPE, 1956, p. 31) 


\section{Revista Solta a Voz, v. 20, n. 2}

Ainda que tal escolha mostrasse o reconhecimento de Delgado de Carvalho como autoridade científica, demonstrava uma outra rede que unia esses intelectuais: a admiração mútua e o afeto. Companheiros da Associação Brasileira de Educação (ABE), Gustavo Lessa, Anísio Teixeira e Fernando de Azevedo se uniam novamente na realizaçáo de mais esse projeto. Juntos, durante anos compartilharam a expectativa de que a educação poderia transformar a nação, o que Brandão (1992, p. 100) caracteriza como um idioma geral que essa primeira geração de educadores profissionais possuía e que tinha como base a trilogia ciência, progresso e civilização:

Ao defender o tratamento dos problemas de educação cientificamente, define o lugar da cidade letrada acima das contingências espaço temporais e políticas, esta situação é conferida à ciência à condição de garantir a igualdade de oportunidades na seleção daqueles que formarão a hierarquia das capacidades, própria à civilização técnica.

\section{EMBATES ACADÊMICOS}

Foi mantida ampla correspondência entre os avaliadores de História Geral e seu autor. Ao estudar os manuais produzidos para o projeto da Caldeme, Munakata (2004) teve acesso aos arquivos do INEP, em Brasília, onde pôde analisar pareceres, cartas, memorandos e tantos outros documentos que compóem esses bastidores. No caso de Delgado de Carvalho, foram encontradas cartas endereçadas a intelectuais da USP, em particular Eurípedes Simóes de Paula, Eduardo d'Oliveira França e Alice P. Canabrava, encarregando-os de emitir pareceres sobre o seu projeto.

Nestas cartas, todas contêm um texto padronizado, explicita-se que os manuais a serem produzidos teriam por objetivo apresentar uma concepçáo da matéria a ser ensinada e do método de ensiná-la que permitisse satisfazer melhor as necessidades reais do adolescente, e estimulasse mais a sua capacidade de reflexão que sua memória. Como se trata de trabalhos sem nenhum poder coercitivo e que serão oferecidos como simples sugestóes, os autores não ficam adstritos nem aos programas, nem à seriação oficial. (Munakata, 2004, p. 520)

Utilizando Gustavo Lessa como intermediário, é feita grande troca de correspondências entre os intelectuais encarregados de elaborar os 
manuais e seus avaliadores. Nelas já ficam claras as várias concepções de ciência. Mais do que críticas a Delgado de Carvalho, essas cartas relatam o esforço de um grupo de historiadores em se legitimar diante do campo científico já constituído. Para Bourdieu (1983), o eterno monopólio do capital científico não existe, sendo este objeto de constante disputa. $\mathrm{O}$ campo define a cada agente as estratégias a partir da posição que eles ocupam em sua estrutura. Assim, os novatos que desejam derrubar a ordem estabelecida optam pelas estratégias de subversão, tendo contra si toda a lógica do sistema, fazendo então investimentos a longo prazo.

Os avaliadores do manual de história geral de Delgado de Carvalho representavam os novos historiadores do Brasil. Formados nos primeiros cursos universitários de Ciências Sociais, tinham uma perspectiva diferente da geraçáo anterior, ainda autodidata, e, por isso, defendiam uma nova linha de atuação pedagógica. Mestres franceses como Fernand Braudel, Émile G. Leonard, Lucien Febvre, Émile Coonaert, Jean Maugué, Pierre Monbeig, Claude Lévi-Strauss, Paul Arbousse Bastide, Pierre Deffontaines, entre tantos outros, proporcionaram-lhes uma formação que rompia com os estudos históricos e geográficos até então realizados, pois delimitavam novos métodos e objetos. O depoimento de Amélia Americano Domingues de Castro (apud Nadai, 1993, p. 154), aluna do curso de História da USP nesse período, ajuda a dimensionar essa ruptura:

Quando entrei na Faculdade, levei um choque com os professores franceses [...] Eles ministravam cursos monográficos, eram extremamente exigentes com o planejamento das aulas, portavam sempre fichas e se preocupavam em nos ensinar o método do trabalho do historiador. Eles não nos ensinavam, por exemplo, a elaborar um fichamento bibliográfico. Isto, nos ensinavam pelo feed-back que traziam da análise dos trabalhos e das provas. Todavia, em classe, analisavam documentos, fazendo uma leitura cuidadosa e interpretativa [...] Em História do Brasil era uma outra história, bem diferente da veiculada nos cursos de História Ibérica ou de História da Europa Ocidental. O professor, nas aulas, era dissertativo, apresentava uma riqueza de detalhes, de pormenores, de datas e de aspectos pitorescos. Vivia contando anedotas sobre os personagens estudados. Quanto à História da Civilização Americana foi uma terceira vertente. Era ministrada por um jornalista e professor. Era uma aula muito discutida, dialogada e a literatura era mais leve, porque ele admitia artigos de jornal, polêmicas que estava se desenrolando; não se recusava trabalhar o conflito. 
A história, tal como Delgado de Carvalho a encontrou ao chegar no início do século ao Brasil, tinha como base a simples memorização dos fatos, como sinônimo de conhecimento. Para saber, era preciso decorar datas e nomes transmitidos pelo professor e pelos livros, com pouca reflexão do que significavam. Na década de 1920, com o fortalecimento do movimento escolanovista, há uma preocupação maior com o método de interpretação, considerada por ele uma das mais importantes funçóes, devendo a memorizaçáo ser superada. O aluno deveria ter como base um quadro sistematizado dos acontecimentos e deveria ter o livro como consulta, não precisando recorrer à memória apenas. A leitura e a interpretação dos fatos eram importantes objetivos a serem alcançados. O estudo de história geral deveria estar a serviço do conhecimento não só da nação, mas da civilização como um todo:

É, pois a coletividade nacional que mais se recomenda; entretanto, não devem ser evitadas referências freqüentes a outras coletividades, isto é, a outras naçôes, principalmente quando vizinhas ou que interessam particularmente à História Nacional pelos serviços que prestaram à civilização (Grécia, Roma) ou pelos laços culturais e étnicos Portugal que criaram um patrimônio comum. (Delgado de Carvalho, 1957, p. 102)

Os historiadores da década de 1950, como destaca Nadai (1993), direcionavam a finalidade do ensino de história para o aprofundamento dos fundamentos científicos, assim como para a formação do espírito crítico dos alunos. Os alunos de Braudel, a partir do contato com a perspectiva da Escola dos Annales, defendiam a superação da história-narração pela história-problema. Elegendo novos objetos de estudo, os personagens isolados deveriam ser abandonados para considerar aspectos coletivos. Para tal, deveriam ser consideradas também as dimensóes econômica e social, bem como a mentalidade em seu tempo.

Os bastidores de elaboração dos manuais da Caldeme são cercados de conflitos, como demonstram a correspondência entre Delgado de Carvalho, Gustavo Lessa e Eurípedes Simôes de Paula. Este, incumbido da avaliação dos manuais, cursou História e Geografia entre 1934 e 1936 na Universidade de São Paulo (USP), onde se tornou professor catedrático de História da Civilização Antiga e Medieval em 1946. Representando o pensamento da nova geração de historiadores, fundou a Revista de História e a Associação dos Professores Universitários de História. 
O ofício e seu rascunho, elaborados por Delgado de Carvalho a Simóes de Paula e guardados pela família com outros documentos pessoais, dá a dimensão do enfrentamento ocorrido entre o educador e o historiador da USP. Ao trabalhar com esse tipo de documentação, é importante considerar as perspectivas de Gomes (2004), que chama atenção para o fato de a correspondência, ao contrário de outros textos, ter um destinatário específico, com quem se estabelece relaçóes:

[...] ela implica uma interlocução, uma troca, sendo um jogo interativo entre quem lê - sujeitos que se revezam, ocupando os mesmos papéis através do tempo. Escrever cartas é assim dar-se-a-ver, é mostrar-se ao destinatário, que está sendo visto pelo remetente, o que permite um tête-a tête, uma forma de presença (física inclusive) muito especial. (Gomes, 2004, p.19)

A versão inicial da carta de Delgado de Carvalho tinha como objetivo comunicar a sua desistência da proposta de escrever o manual de história geral: "Nestas condiçôes permita que seja aceita a minha desistência da execução do trabalho que eu planejei, pois não quero comprometer os amigos que se tenham empenhado em ter a minha colaboração" (Carta de Delgado de Carvalho a Simóes de Paula, 27 de outubro de 1953). A redação do rascunho, pontuada pela emoção e pela indignação, aponta como maior justificativa para a tomada dessa decisão o fato de os professores paulistas não considerarem o método a questão principal dos manuais:

O parecer apresentado, a 8 de outubro do corrente ano, pelo eminente catedrático da Universidade de S. Paulo Dr. Simôes de Paula, é uma peça que merece alguns comentários.

Em primeira página, principia o ilustre autor que acha desnecessário levar em conta, no seu parecer, os aspectos didáticos da questão. É realmente de estranhar semelhante atitude, pois o aspecto didático é precisamente o mais importante num trabalho destinado à orientação dos mestres. (Rascunho da carta de Delgado de Carvalho a Simóes de Paula, 1953)

Delgado de Carvalho sempre se refere a Simóes de Paula com um tom pejorativo, como eminente catedrático ou ilustre autor, em um 


\section{Revista Solta a Voz, v. 20, n. 2}

suposto reconhecimento de autoridade que as críticas desmentem. $\mathrm{Na}$ realidade, o intelectual deixa clara sua posição de não aceitar as críticas de alguém que, a seu ver, demonstra desconhecimento das questôes pedagógicas tidas como fundamentais:

As ligeiras considerações que fez o catedrático de História Antiga e Medieval da Universidade de S. Paulo constituem uma preleçáo acaciana sobre o que deve ser o ensino de História e uma série de críticas que traduzem o mais completo desconhecimento da didática moderna. (Rascunho da carta de Delgado de Carvalho a Simóes de Paula, 1953)

A resposta oficial tem um tom bem mais contemplativo. Tudo leva a crer que, no intervalo das duas redaçóes, Delgado de Carvalho tenha sido convencido por Gustavo Lessa, a quem se refere nos dois escritos como amigo e colega, a continuar a elaboração dos manuais em nome de um ideal maior:

Li com atenção e interesse o parecer do eminente catedrático da Universidade de Sáo Paulo, Dr. Simóes de Paula, datado de 8 do corrente e que teve o amigo a gentileza de me comunicar.

Tive a satisfação de ver que as idéias expressas na primeira parte do Parecer coincidem com as que implicitamente se acham contidas na justificativa prévia que apresentei ao amigo, mas que não chegaram ao conhecimento do autor do parecer. (Carta de Delgado de Carvalho a Simóes de Paula, 27 de outubro de 1953)

A justificativa a que se refere Delgado de Carvalho é o plano didático elaborado para os manuais, em que expóe uma extensa lista fundamentada em uma versão tradicionalista da história, a partir da exposição de fatos e sua comprovação por documentos selecionados pelo autor. Ainda na orientação metodológica aos professores, transparece o olhar do determinismo histórico.

\section{Plano didático}

1. A Obra compreenderá 16 Unidades, divididas em 2 ou 3 partes cada uma. O volume será de cerca de seiscentas pgs, em tipos variados. Segundo a categoria de informaçóes apresentadas. 
2. O compêndio propriamente dito é constituído pela narrativa de cada Unidade, segundo o programa anexo. Será escolhido para esta parte central de cada Unidade, o tipo maior. Em seguida, virão as Notas, em tipo menor, que sáo os complementos e as explicaçóes fornecidas aos professores.

3. Em cada Unidade, a narrativa é precedida de uma preparação da aula, que abrange:

a) Os objetivos visados no conhecimento dos fatos históricos a focalizar.

b) O quadro geográfico dos acontecimentos e sua interpretação econômica e social.

c) A perspectiva histórica: relaçóes de causalidade.

Motivação, processos e métodos de despertar interesse. Palavras-chaves a discutir.

4. Em cada Unidade, a narrativa e suas notas serão seguidas de uma documentação ou contato com a realidade histórica:

a) Mapas, Datas e Cronologia - Ilustraçôes.

b) Resumos biográficos de personalidades da época.

c) Leituras complementares, escolhidas em autores fidedignos.

d) Textos históricos a explicar.

e) Bibliografia sumária para professor e aluno.

5. Processos de Verificação da Aprendizagem.

Exercícios - Testes - Tópicos de Dissertaçôes.

(Delgado de Carvalho, 1950, s.p.)

Para Munakata (2004), a questão que pontua o conflito entre os que se dedicam à história a partir da década de 1950 é a priorização dos aspectos didáticos à discussão acadêmica. Alguns intelectuais chegam a basear seu discurso na seleção dos termos mais adequados para definir determinado contexto histórico, sem considerar o aspecto pedagógico.

As críticas elaboradas por Eurípedes Simões foram iniciadas pela visão apenas política da história. Para os adeptos da chamada História Nova, isso era considerado um grave erro, na medida em que não dimensionava corretamente a realidade do passado. A história deveria trabalhar com uma cultura geral, a fim de aproximar o estudante da realidade histórica, que deveria ser abordada pelo manual a partir de noções de história da arte, filosofia e literatura, de forma integrada. Munakata (2004) destaca a expressão usada pelo historiador, paisagem histórica, para demonstrar a afinidade de suas ideias com a Escola dos Annales. 


\section{Revista Solta a Voz, v. 20, n. 2}

A resposta, inicialmente elaborada por Delgado de Carvalho, é enfática. Náo reconhece a crítica sobre a ausência da paisagem histórica como uma inovação e identifica essa dimensão em seu plano didático, mas com outro nome: quadro geográfico. Assim, considera tudo apenas uma questão de nomenclatura, que pouco acrescenta à sua obra; o importante era como fazê-lo didaticamente:

Na terceira página, neste deserto de idéias práticas que constitui o parecer, encontramos um oásis consolador: "Procurar trazer o campo da História para mais perto possível dos "estudantes" é um conselho; "Localizar no tempo e no espaço" é o segundo aviso; "Proporcionar também um fundo de cultura geral" é o terceiro conselho... Muito bem: aí está com suas três partes integrantes, gema, clara e casca, o ovo de Colombo!

Outra idéia recomendável: Evitar, com falha grave, a apresentação da matéria com predominância absoluta de seu aspecto político. "A advertência não é nova, é mesmo um tanto bolorenta; já ouvi dizer no século passado!" (Rascunho da carta de Delgado de Carvalho a Simóes de Paula, 1953)

Na redação final, a emoção dá lugar à razão:

Estou perfeitamente de acôrdo em "procurar trazer o campo da História para mais perto possível dos estudantes" de "localizar no tempo e no espaço" os ensinamentos ministrados, e a "proporcionar também um fundo de cultura geral" aos educandos. Longe de mim, por fim, a idéia de uma "apresentação da matéria com predominância absoluta de seu aspecto político". Se me fosse permitida aqui uma referência pessoal, eu me limitaria a lastimar de não ter enviado ao meu prezado colega de São Paulo um exemplar de minha "Didática das Ciências Sociais", publicada pela Secretaria de Educação de Minas Gerais e traduzida para espanhol pela Editorial Capeluz de Buenos Aires, assim como de não ter mandado exemplares de minhas "Sumulas de História" editadas pela Companhia Editora Nacional de Sáo Paulo. Meus métodos de ensino teriam assim chegado ao conhecimento de meu jovem colega... digo "jovem" porque sou professor de História desde 1903! (Carta de Delgado de Carvalho a Simóes de Paula, 27 de outubro de 1953)

Ainda que mais racional, a resposta não afasta do enfrentamento de Delgado de Carvalho a tentativa de subversão à sua autoridade do campo. Para isso, o intelectual expóe seu capital cultural citando suas publicaçóes 
nacionais e internacionais e classifica seu interlocutor como novato diante de um campo que já o consagrou.

Outra crítica ao plano didático é a relação estabelecida de causa e efeito. Para o crítico, essa não era a função da história; ao utilizar esse recurso, estaria afastando o mundo histórico e a ação do homem sobre o meio de uma dimensão maior. O que, a princípio, Delgado responde: "[...] catedrático eminente rejeita as mais modestas tentativas de explicação, pois como diz Leibnitz nada acontece que não tenha uma causa ou pelo menos uma razão determinante" (Rascunho da carta de Delgado de Carvalho a Simóes de Paula, 1953). Na versão oficial, a discordância é mantida: "[...] admito que nem sempre estamos em condiçốes de dar todas as explicaçóes, mas algumas relaçóes de causalidade me parecem úteis. Por exemplo, o estudo do Antigo Regime que precedeu a Revolução Francesa explica muitas feiçóes desta Revolução..." (Carta de Delgado de Carvalho a Simóes de Paula, 27 de outubro de 1953).

Ainda nessa fase, foi submetido à crítica o plano de unidades que apresentava a divisão dos conteúdos.

\section{Plano de unidades}

I) Os quatro vales da antiguidade: Nilo, Mesopotâmia, Ganges e Hoang-ho.

II) A antiguidade clássica no Mediterrâneo: A Grécia e Roma.

III) $O$ Progresso da Idade Antiga às Ciências, Letras e Artes.

IV) A transição medieval- As invasões - Os Árabes- A conversão dos Bárbaros.

V) A Idade Feudal e seu declínio - O Sacerdócio e o Império - As Cruzadas

- O Estado Anglo-Francês.

VI) Contribuição da Idade Média ao Progresso das Ciências, Letras e Artes. VII) O Renascimento, as Invençôes e os Descobrimentos; o Novo Mundo. VIII) A Reforma, a Reação Católica e as lutas religiosas.

IX) O Absolutismo no Ocidente; As rivalidades Dinásticas e as Rivalidades Coloniais.

X) As Revoluçóes Inglesas e o Parlamentarismo. O despotismo Esclarecido. XI) A Revolução Francesa e o Império Napoleônico - A independência das Américas.

XII) A Idade Moderna e o Progresso no Mundo.

XIII) A Reação Monárquica, o Liberalismo e a Revolução Industrial. 


\section{Revista Solta a Voz, v. 20, n. 2}

XIV) Democracia e Nacionalismo - A preponderância Alemã - A Questão do Oriente.

XV) Expansão e Colonialismo - Partilha da África - Formação das Alianças.

XVI) As Grandes Guerras do Século XX e a trégua de vinte anos.

XVII) As Américas - Os Estados Unidos, o Brasil e as Naçóes Latinas.

XVIII) O Extremo Oriente - O Pacífico - Japão, China e Índia. - O Oriente Médio.

XIX) O Mundo Contemporâneo - As Naçóes Unidas e a Evolução de Após-Guerra.

XX) A Evolução das Ciências, Letras e Artes no Mundo Contemporâneo. (Delgado de Carvalho, 1953, s.p.)

Nesse aspecto, a maior crítica em relação à seleção dos conteúdos feita pelo autor é quanto à europeização da história, ou seja, ao fato de a Europa ser o centro dos acontecimentos, o que Delgado inicialmente vê com indignação:

Na página 6, assistimos a uma chuva torrencial no molhado - Trata-se da deseuropeização da História. "Não pensamos ser fácil”, diz Racker - muito ao contrário, julgo eu ser facílimo e muitíssimo necessário, com já tentei fazer em pequenos tijolos verdes ...

É principalmente na História Contemporânea que está o quê da questão. Por isso mesmo, no Plano, o eminente catedrático verá que, das 7 unidades, 3 são relativas à Europa, 1 é mundial e 3 são relativas à Europa e ao Oriente. A quota européia fica reduzida assim a 50\%. (Rascunho da carta de Delgado de Carvalho a Simóes de Paula, 1953)

Mas depois responde em tom de concordância: "O Parecer recomenda acertadamente, a "deseuropeização" da História Contemporânea". Para Guimarães (1993), esse era um aspecto reivindicado pelos historiadores na década de 1950, mas que não foi superado. O eurocentrismo estava presente não só nos programas escolares, que na Resolução de 19 de dezembro de 1962 divide o currículo em História Antiga, Média, Moderna e Contemporânea, como nas pesquisas históricas.

Em História geral: antiguidade (1956), o primeiro da série didática encomendada pelo INEP e editado pelo CBPE, com apoio do Ministério da Educação (MEC), o autor deixa claro, logo em seu preâmbulo, que não teve a intenção de trabalhar com um conhecimento inédito, e sim reunir 
informaçóes já conhecidas dos professores, mas organizadas em um plano de trabalho, que seria uma sugestão de roteiro a ser seguido em sala de aula. A seguir, descreve-o passo a passo, não sem antes abrir um parêntese para lembrar com satisfação que tal divisão foi elaborada por Anísio Teixeira. O detalhamento com que é feita a descrição pressupóe a intenção prescritiva do autor: primeiro estabelece os objetivos da unidade e ainda sugere que esta seja desenvolvida em sala de aula durante pelo menos três semanas de aula. Tal etapa é seguida do processo histórico, que são conceitos considerados pelo autor como básicos, e que o professor deve dominar. Depois há várias formas de exposição do conteúdo, dividido em aspectos político, econômico e social, sob forma de linha do tempo, com os fatos organizados de forma cronológica, e, por fim, as leituras complementares, nas quais são sugeridos "textos escolhidos em bons autores que podem ser lidos e comentados com os alunos" (Delgado de Carvalho, 1956, p. 13).

Ao final do preâmbulo, Delgado de Carvalho (1956, p. 15) expóe os motivos pelos quais elaborou o livro de consulta apenas para os mestres:

O livro-compêndio a ser adotado para o uso do aluno, hoje em dia, deve ser claro, bem informado, bem escrito, bem apresentado, mas precisa também ser conciso, digamos curto, isto é, pouco volumoso, para ser barato, mas antes de tudo, para ser acessível e representar uma disciplina que pode, sem grande esfôrço e trabalho, ser ministrada durante o ano letivo. $\mathrm{O}$ mal do ensino de História é, muitas vêzes, o fato de ser incompleto e falho. $\mathrm{O}$ "compêndio pequeno" deve, pois, ser visado no ensino secundário. Ora, o mestre náo se pode satisfazer, para suas aulas, de um compêndio pequeno. A necessidade de completá-lo se impóe a ele. É precisamente o objetivo dêste trabalho auxiliá-lo nisso, poupando seu tempo.

Os argumentos do autor atingem o mercado editorial, que, para ele, levaria mais em conta o lado comercial do que a qualidade do conteúdo dos livros. Os estudos de Halewell (1985) sobre o livro no Brasil apontam que as editoras justificavam essa opçáo alegando o alto custo do livro didático e o sistema de livre escolha do professor, obrigando-as a manter grandes estoques que, muitas vezes, ficavam encalhados.

O primeiro volume da coleção História Geral: Antiguidade, editada pelo INEP na série Guias de ensino, em 1956, foi entregue com atraso, justificado da seguinte forma pelo autor, quando questionado pelo diretor da Caldeme: 


\section{Revista Solta a Voz, v. 20, n. 2}

A obra realizada não é das que só uma pessoa possa se incumbir de elaborar com prazo marcado, sem poder contar com auxiliares para pesquisa, resumo, notas, datilografia, traduçóes e organizaçáo de mapas. Pelo menos uma funcionária competente nos assuntos tratados deverá ser requisitada para semelhante trabalho. (Carta de Delgado de Carvalho a Gustavo Lessa, 22 de dezembro de 1955)

$\mathrm{O}$ argumento utilizado por Delgado de Carvalho expóe as dificuldades encontradas na elaboração do manual, como a pressão sofrida para que concluísse o trabalho. No mesmo documento em que responde a uma solicitação de alteração do contrato com prazo de seis meses para a entrega dos demais volumes, é posto outro problema, os atrasos no pagamento: "Quanto à remuneração, não vejo objeção a que seja fixada de acôrdo como proposto no terceiro adendo. Apenas não desejaria que figurassem prorrogaçóes, mas apenas, três quotas correspondendo às três obras encomendadas" (Carta de Delgado de Carvalho a Gustavo Lessa, 22 de dezembro de 1955). O não cumprimento dos prazos acarretaria o desconto de $\operatorname{Cr} \$ 10.000,00$ por mês de atraso, do total da remuneração de Cr\$150.000,00 previstos inicialmente.

\section{Novos CAMINHOS DA HISTÓRIA}

A história das disciplinas escolares ganha cada vez mais diferentes olhares. Os estudos realizados nos ajudam a compreender práticas, conteúdos, materiais que fizeram parte do cotidiano das nossas salas de aula. $\mathrm{O}$ processo, contudo, não é simples. $\mathrm{O}$ pouco espaço reservado à memória em nossas escolas é uma barreira. Pouco se guardou, e dificilmente se consegue encontrar cadernos com exercícios registrados por alunos, cartazes ou planejamentos elaborados por professores. À história cabe a tarefa de buscar outros caminhos.

Nesse aspecto, a correspondência entre Carlos Delgado de Carvalho e seus avaliadores da Universidade de São Paulo representa um lugar de memória, e, com os manuais, constitui importante fonte histórica. Ao estudá-la é possível perceber não só as disputas ocorridas no campo científico, como a relação estabelecida por esses intelectuais entre o saber acadêmico e as disciplinas escolares. A obra de Delgado de Carvalho mostra a constante preocupação em conjugar a necessidade do aluno com o conteúdo e o método, criando um conhecimento específico que, por sua vez, não se confundia com a simplificação do saber. À nova geração de 
historiadores da década de 1950, o peso da mudança. Ao elegeram novos objetos de estudo, foram acusados de não privilegiar a questão didática, mas não é possível deixar de perceber a preocupação com os conteúdos escolares em suas críticas ao velho mestre.

Mais do que isso, as discussóes entre esses intelectuais em busca pelo reconhecimento do campo mostram ansiedades, dúvidas, alegrias e ressentimentos, sem os quais não seria possível compreender o passado, aspectos que a legislação e os programas oficiais não demonstram. Novos olhares, mais histórias.

\section{Fontes primárias}

Carta de Delgado de Carvalho a Gustavo Lessa (Rio de Janeiro 22 de dezembro de 1955).

Carta de Delgado de Carvalho a Simóes de Paula. (Rio de Janeiro, 27 de outubro de 1953).

Rascunho da carta de Delgado de Carvalho a Simóes de Paula (Rio de Janeiro, 1953).

\subsection{2) Produção intelectual}

DELGADO DE CARVAlHO, Carlos. Plano didático. (Rio de Janeiro, 1950).

. Plano de unidades. (Rio de Janeiro, 1953).

\section{REFERÊNCIAS}

BOURDIEU, Pierre. O campo científico. In: ORTIZ, Renato. (Org.) Sociologia. São Paulo: Ática, 1983.

1989.

. O poder simbólico. Rio de Janeiro/Lisboa: Bertrand Brasil/Difel,

CBPE. Educação e Ciências Sociais. Rio de Janeiro, v.1, n. 1, mar. 1956.

COELHO, Patrícia. A voz do mestre: trajetória intelectual de Carlos Delgado de Carvalho. (Dissertação). Universidade do Estado do Rio de Janeiro. Rio de Janeiro, 2007. 
DELGADO DE CARVALHO, Carlos. Geographia do Brasil. Rio de Janeiro: Emp. Photo-Machanica do Brasil, 1913.

. História geral: Antiguidade. Rio de Janeiro: Editora INEP, 1956.

1959. . História geral: Idade Média. Tomo I. Rio de Janeiro: Editora INEP, INEP, 1959.

. História geral: Idade Média. Tomo II. Rio de Janeiro: Editora $\overline{1966 .}$. História geral: Idade contemporânea. Rio de Janeiro: Editora INEP,

GOMES, Ângela de Castro. Escrita de si, escrita da História: a título de um prólogo. In: . (org.). Escrita de si, escrita da história. Rio de Janeiro: Editora FGV, 2004.

HALEWELL, Laurence. O livro no Brasil e sua história. São Paulo: Ed. Universidade São Paulo, 1985.

MENDONÇA, Ana Waleska; BRANDÃO, Zaia (orgs.). Por que não lemos Anisio Teixeira? Uma tradição esquecida. Rio de Janeiro: Ravil, 1997.

MUNAKATA, Kazumi. Dois manuais de história para professores: histórias de sua produção. In: Educação e pesquisa, São Paulo, v.30, n.3, p.513529, set./dez. 2004.

NADAI, Elza. O ensino de história no Brasil: trajetória e perspectiva. In Revista Brasileira de História, São Paulo, v.13, n.25/26, set.92/ago.93.

Recebido em: 30 jun. 2009

Aceito em: 16 nov. 2009 